MATEC Web of Conferences 6, 05002 (2013)

DOI: $10.1051 /$ matecconf/20130605002

(C) Owned by the authors, published by EDP Sciences, 2013

\title{
Spalling of concrete due to fire exposure: A coupled fracture mechanics and pore pressure approach
}

\author{
B.B.G. Lottman ${ }^{1, a}$, E.A.B. Koenders ${ }^{2,3}$, C.B.M. Blom ${ }^{1,4}$ and J.C. Walraven ${ }^{1}$ \\ 1 Stevin II lab, Delft University of Technology, The Netherlands \\ ${ }^{2}$ Microlab, Delft University of technology, The Netherlands \\ ${ }^{3}$ COPPE-UFRJ, Rio de Janeiro, Brazil \\ ${ }^{4}$ Municipality of Rotterdam, PM\&E, The Netherlands
}

\begin{abstract}
In this paper results are presented from a by STW funded research project "spalling of concrete due to fire exposure" between Eindhoven University of Technology and Delft University of Technology and aimed at developing an integral spalling model. In this paper two coupled Finite Element based models are presented in which the first model describes the physical behaviour of concrete and is used to determine the temperature and pore pressure development and the second model describes the fracture mechanics behaviour of concrete and is used to determine the crack development.
\end{abstract}

\section{INTRODUCTION}

During fire exposure of a concrete structure several interacting processes develop which have a chemical, physical and mechanical bases $[1,2]$ as depicted in Figure 1. The chemical behaviour develops at the micro level of the cement paste due to the evaporation of capillary water and the dehydration processes [3]. The resulting progressive weakening with temperature of the porous microstructure [3] tends to decrease the strength and stiffness [4] and increases the porosity and the intrinsic permeability $[5,6]$. The influence of the temperature increase on the aggregate particles is characterised by the thermal stability which mainly dependents on the chemical composition [7]. The low conductivity of concrete combined with the high temperature exposure results in the development of a temperature gradient across the cross section [8]. This temperature gradient combined with the evaporation of liquid water in the confined space of the pores results in the development of pore pressures [9]. The physical behaviour at the micro/meso level is determined by the pore pressure gradients which induce the flow of gas and liquid water towards the heated surface and into the cross section $[9,10]$. The development of the temperature and pore pressure [11] in a dehydrating cement paste is combined with the structural macro behaviour to form the mechanical response of the concrete. The partial restrainment of the thermal deformations leads to a stress distribution across the concrete cross section $[12,13]$ and crack development which could possibly influence the pore pressure build-up. The development of these interacting processes could lead to a spalling mechanism in which part of the heated surface layer becomes unstable resulting in fracture and sudden release of stored energy.

\section{SPALLING MODEL}

The presented spalling model consists of two coupled models which have a physical and fracture mechanics bases respectively. The first model determines the physical behaviour of concrete resulting in

${ }^{a}$ Corresponding author: Delft University of Technology, Faculty of Civil Engineering and Geosciences - Stevinweg 1, $2628 \mathrm{CN}$ Delft, The Netherlands, e-mail: B.B.G.Lottman@tudelft.nl

This is an Open Access article distributed under the terms of the Creative Commons Attribution License 2.0, which permits unrestricted use, distribution, and reproduction in any medium, provided the original work is properly cited. 


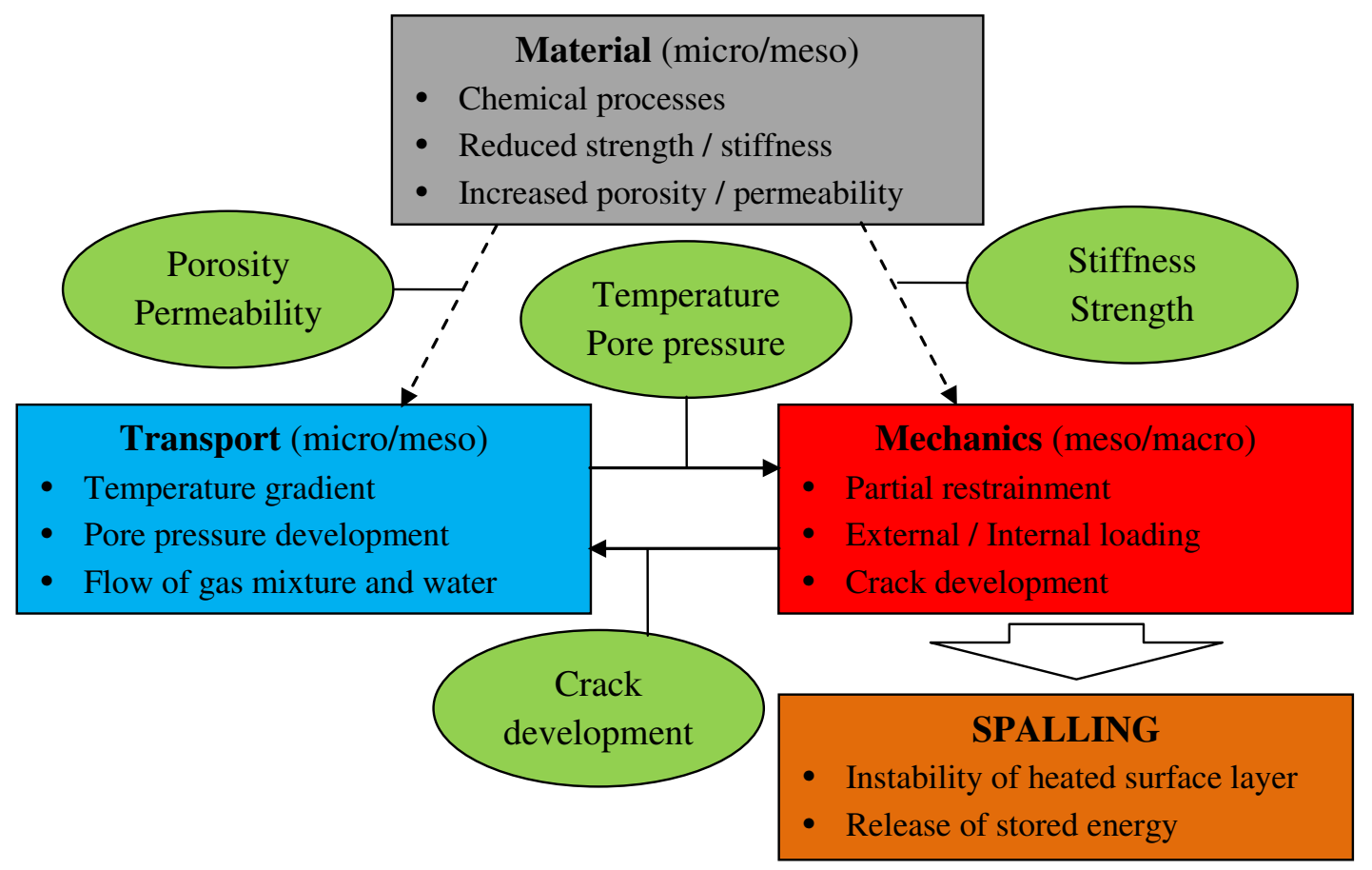

Figure 1. Schematic overview of the processes in heated concrete leading to spalling $[14,15]$.

the temperature and pore pressure distribution across the cross section. The second model determines the fracture mechanics behaviour of concrete resulting in the overall deformations, stress distribution and crack development. The coupling between both models consists of the internal loading by temperature and pore pressure build-up and the local crack development influencing the intrinsic permeability of the material.

$$
\begin{aligned}
& \rho C \frac{\partial T}{\partial t}+\nabla .(-k) \nabla T=-H_{v a p} \frac{\partial \bar{\rho}_{\text {vap }}}{\partial t}-H_{\text {dehydr }} \frac{\partial \bar{\rho}_{\text {dehydr }}}{\partial t} \\
& \frac{\partial\left(n S_{g} \rho_{g a}\right)}{\partial t}+\nabla .\left[n S_{g} \rho_{g a} \frac{-K_{\text {rel,g}} K_{\text {int }}\left(1+\frac{b}{P_{g}}\right)}{\mu_{g}} \nabla P_{g}\right]=0 \\
& \frac{\partial\left(n S_{g} \rho_{g w}\right)}{\partial t}+\nabla \cdot\left[n S_{g} \rho_{g w} \frac{-K_{r e l, g} K_{\text {int }}\left(1+\frac{b}{P_{g}}\right)}{\mu_{g}} \nabla P_{g}\right]=\frac{\partial \bar{\rho}_{v a p}}{\partial t} \\
& \frac{\partial\left(n S_{w} \rho_{w}\right)}{\partial t}+\nabla \cdot\left[n S_{w} \rho_{w} \frac{-K_{r e l, w} K_{\text {int }}}{\mu_{w}} \nabla P_{w}\right]=-\frac{\partial \bar{\rho}_{v a p}}{\partial t}+\frac{\partial \bar{\rho}_{\text {dehydr }}}{\partial t} .
\end{aligned}
$$

The physical behaviour is based on a multi phase porous material in which liquid water and a gas mixture of dry air and water vapour is present [16-18]. Each of these phases is described by a mass balance equation which are combined with an equation of energy assuming thermodynamic equilibrium [19-21]. The resulting system of 4 coupled differential equations depicted in equation (1) is solved 


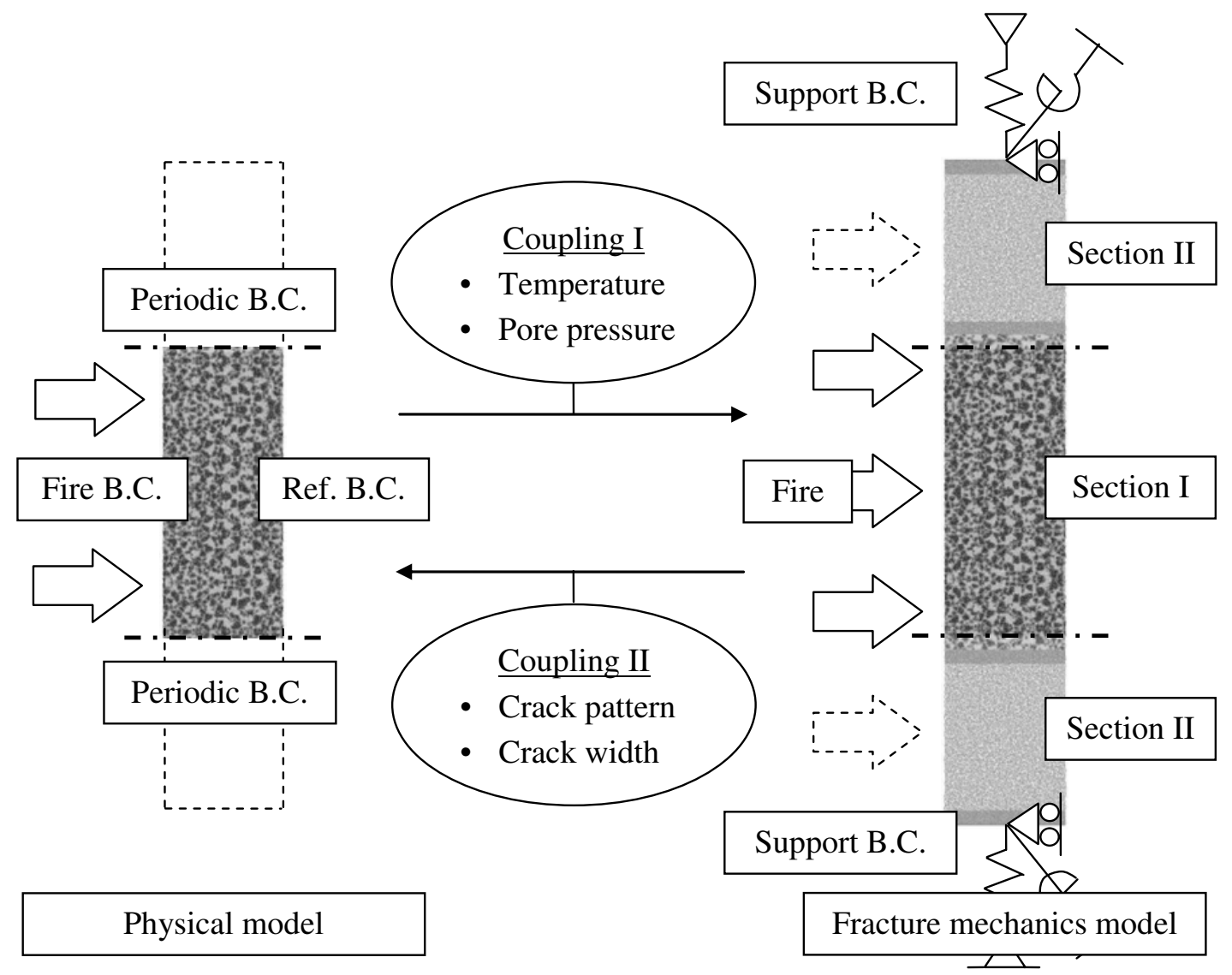

Figure 2. Schematic overview of the spalling model.

numerically by the Finite Element Method (FEM) [22]. The material description across the cross section consists of aggregate particles, mortar and interface zones. These constituents determine the temperature dependent material properties of the randomly distributed small 1D elements across the cross section. The aggregate particles are thereby assumed to by impermeable. The inclusion of local crack development requires the evaporation of the liquid water to be based on physical considerations taking the availability and development of energy, liquid water and water vapour into account. The flow of liquid water and gas is furthermore based on the saturation with liquid water levels. The boundary conditions implemented at the left and right outer edges reflect the fire exposure and the ambient conditions respectively [22]. The top and bottom outer edges are connected by periodic boundary conditions to allow a continuous material description. In Figure 2 an overview of the physical model is depicted.

The fracture mechanics behaviour is based on explicit crack development of the thermally loaded material. This discrete fracture mechanics approach $[23,24]$ is based on the 1D mechanical element commonly referred to as the Bernoulli Euler beam [25] which allows for normal and shear forces transfer as well as moments. The model has a linear elastic bases and assumes crack development by brittle fracture of individual elements [23, 24]. This results in genuine separation of the material by removing fracture elements. Recalculation during fracture of the material results in redistribution and relaxation 


\section{MATEC Web of Conferences}
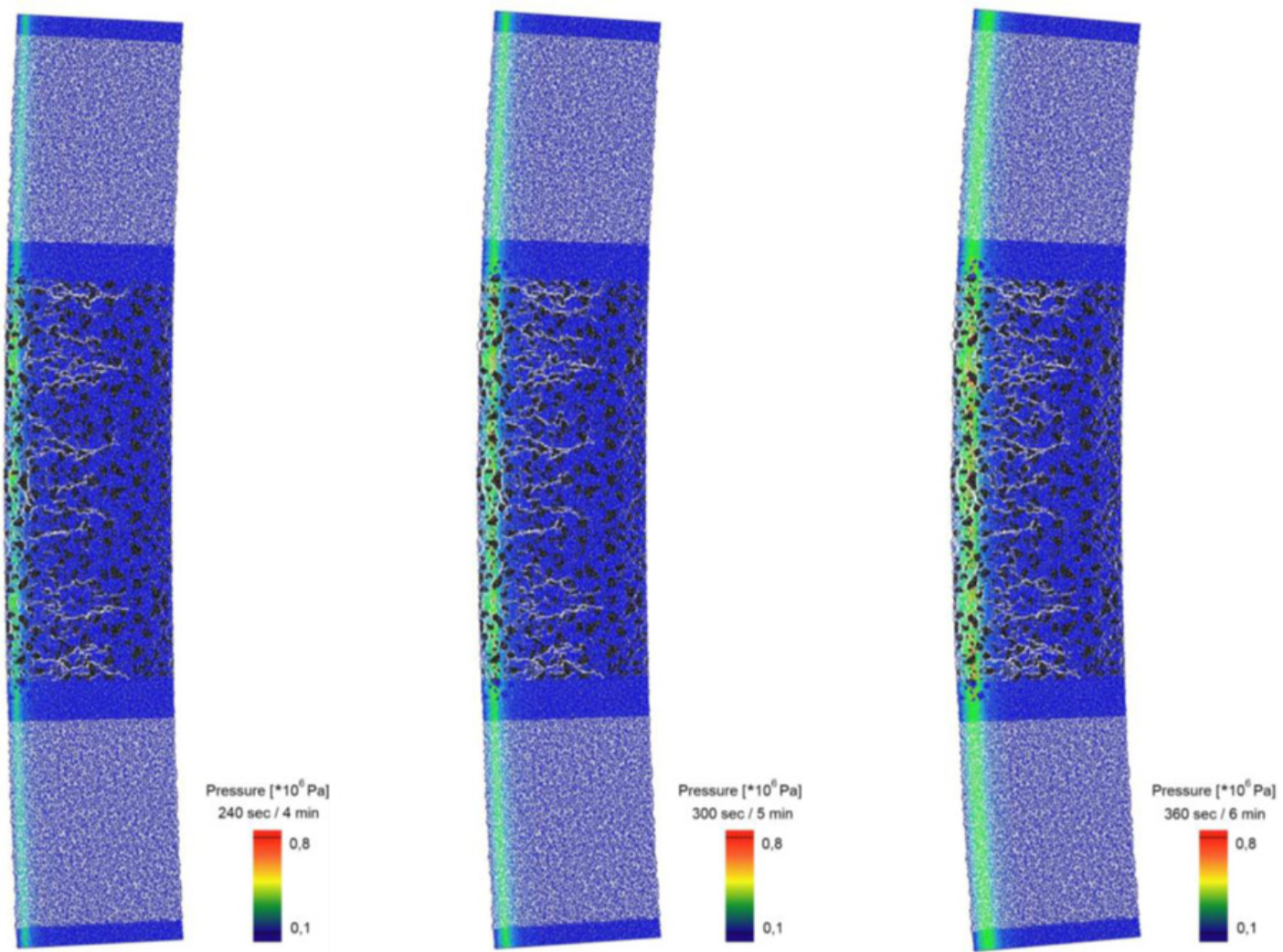

Figure 3. Pressure development after $240 \mathrm{sec} / 4 \mathrm{~min}, 300 \mathrm{sec} / 5 \mathrm{~min}$ and $360 \mathrm{sec} / 6 \mathrm{~min}$.

of the stresses in the surrounding material.

$$
\begin{aligned}
& E A \frac{d}{d x}\left[\frac{d u}{d x}-\varepsilon_{\text {initial }}\right]=-q_{x} \\
& E I \frac{d^{4} w}{d x^{4}}=q_{y} .
\end{aligned}
$$

The uncoupled system of 2 differential equations depicted in equation (2) is again solved by the FEM and randomly implemented across the heterogeneous material description [26]. The thermal loading is reflected by the strain definition which incorporates an initial extensional strain [27, 28]. Each individual element is thereby loaded in extension to account for the local temperature and pore pressure development. The pore pressure only acts as internal loading in the mortar and interface zones surrounding the aggregate particles. The model is implemented for a concrete segment with structural boundary conditions at the top and bottom outer edges. A rigid body combined with a fixed and spring support condition [29] is implemented to account for the deformation behaviour of the segment and the interaction with the surrounding structure. In height direction the segment is divided into three sections in which the explicit crack development is implemented in the middle section to mitigate edge effects by the boundary conditions. The top and bottom sections are included to allow for sufficient height and deformation behaviour of the segment. The mechanical behaviour of these sections is direction dependent [30] and incorporates implicit crack development. In Figure 2 an overview of the fracture mechanics model is depicted. 

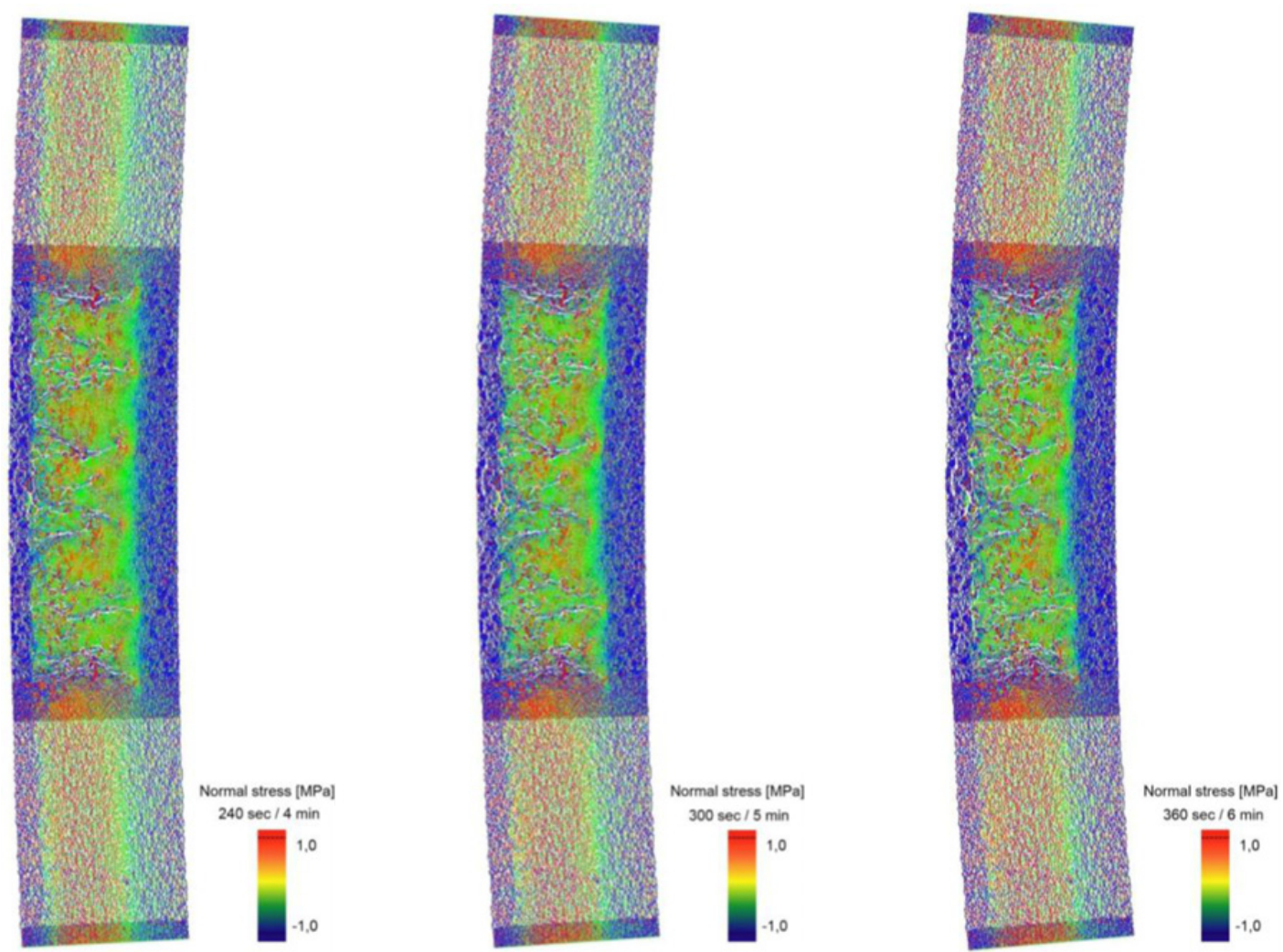

Figure 4. Normal stress development after $240 \mathrm{sec} / 4 \mathrm{~min}, 300 \mathrm{sec} / 5 \mathrm{~min}, 360 \mathrm{sec} / 6 \mathrm{~min}$.

\section{Coupling between the physical and fracture mechanics models}

The physical model is implemented for the middle section in which the aggregate structure and explicit crack development are present. The obtained temperature and pore pressure distribution is implemented as internal loading in the middle section. The average temperature and pore pressure distribution in the middle section is determined and prescribed to the outer sections. This results in the overall temperature and pore pressure distribution across the height of the segment. The explicit crack development in the middle section is used to determine the crack width and the local intrinsic permeability increase. During crack development the physical model is also recalculated to account for the possible pore pressure reduction in the internal loading. In Figure 2 the coupling between both models is indicated.

\section{RESULTS}

In Figures 3 and 4 the pore pressure and normal stress distribution across the concrete segment after 4, 5 and 6 minutes of fire exposure are depicted respectively. The segment is made of Normal Strength Concrete with river gravel aggregate particles (mainly quartz). The saturation with water of the porous microstructure is based on a Relative Humidity of $80 \%$. The fire exposure results in a effective heating rate of $50{ }^{\circ} \mathrm{C} / \mathrm{min}$ in the first 10 minutes. Finally the segment is allowed almost unrestrained thermal deformation by implementing relative small spring stiffness's at the top and bottom outer edges.

The progressive temperature gradient results in the development of a pore pressure peak which in time builds up and shifts into the cross section. The average pore pressure after 6 minutes is around 


\section{MATEC Web of Conferences}

0.45 $\mathrm{MPa}$ with local higher values of around $0.8 \mathrm{MPa}$. These are due to narrow passages between aggregate particles partially impeding the flow of the gas mixture. The width of the pore pressure peak also increases in time dependent on the possibility of the water vapour to escape to the heated surface. The distribution of the aggregate particles thereby affects the flow of the gas mixture. The crack pattern leads to a local reduction of the pore pressure build-up in case of sufficiently increased flow capabilities. The resulting pore pressure peak therefore has a dominate 1D character with local deviations.

The temperature gradient and the pore pressure peak results in the development of a distinctive crack pattern based on the normal stress distribution across the cross section. The partial restrainment of the thermal expansion of the heated surface layer results in a maximum compressive stress of around $-26.0 \mathrm{MPa}$ after 6 minutes of fire exposure. The forced deformation of the unheated centre of the cross section results in a maximum tensile stress of around 5.0 MPa after 6 minutes of fire exposure. This stress distribution results in a relative large number of vertical compressive cracks in the heated surface layer. These further weaken the dehydrated concrete and results in local intrinsic permeability increase. In the centre of the cross section several larger horizontal tensile cracks develop in which the deformations are localised resulting in relaxation of stresses in the surrounding material. The rapidly decaying temperature gradient results in a sharp change in the stress state and colliding of the tensile cracks with the smaller compressive cracks reflected by the diagonal cracks.

The progressive development of the compressive stresses weaken the heated surface layer by extensive crack formation. The pore pressure build-up acts in this cracked and dehydrated surface layer and influences the crack development by local increased thermal loading. However in case of sufficient crack extension and opening the pore pressure build-up also partially mitigates. The thermal instability of the heated surface layer by fracture and release of the stored energy is therefore closely related to this dynamic fracture process. Spalling of concrete is thereby the possible consequence of this mechanism.

The authors like to thank the Dutch National Science Foundation (STW) for financially supporting the research project on "Explosive spalling of concrete". This research project comprised of three PhD Students and was a joint project between Eindhoven University of Technology and Delft University of Technology.

\section{References}

[1] G. A. Khoury and Y. Anderberg, Fire Safety Design - concrete spalling review - report submitted to the Swedish National Road Administration, Sweden, 2000.

[2] J. Horvath, U. Schneider and U. Diederichs, Beiträge zum Abplatzverhalten von Hochleistungsbetonen (in German) - Schriftenreihe Institut für Baustofflehre, Bauphysik und Brandschutz, Heft 11, TU Wien, Vienna, Austria: TU Vienna, Institute for Building Materials, Buildings Physics and Fire Protection, 2004.

[3] C. Alonso and L. Fernandez, "Dehydration and rehydration processes of cement paste exposed to high temperature environments," Journal of materials science, vol. 39, no. 9, pp. 3015-3024, 2004.

[4] RILEM Technical Committee HTC, Behaviour of concrete at high temperatures - State of art report - part 1 - ordinary concrete, Bagneux, France: RILEM publications S.A.R.L., 2004.

[5] J. C. Mindeguia, Contribution expérimentale a la compréhension des risques d'instabilité thermique des bétons (in French) - PhD thesis l'université de Pau et Pays de L'adour, Pau, France, 2009.

[6] M. Zeiml, R. Lackner, D. Leithner and J. Eberhardsteiner, "Identification of residual gas-transport properties of concrete subjected to high temperatures," Cement and Concrete Research, vol. 38, no. 5, pp. 699-716, 2008. 
[7] fib working party 4.3-1, Fire design of concrete structures: materials, structures and modelling state of art report, Lausanne, Switzerland: International Federation for Structural Concrete (fib), 2007.

[8] K. Kordina, Das Verhalten von Stahlbeton- und Spannbetonbauteilen unter Feuerangriff (in German) - Heft 2, Braunschweig, Germany: Institut für Baustoffkunde und Stalbetonbau der Technischen Hochschule Braunschweig, 1963.

[9] P. Kalifa, F. D. Mennetau and D. Quenard, "Spalling and pore pressure in HPC at high temperatures," Cement and Concrete Research, vol. 30, no. 12, pp. 1915-1927, 2000.

[10] G. H. A. Van der Heijden, NMR imaging of moisture inside heated porous building materials $\mathrm{PhD}$ thesis TU Eindhoven, Eindhoven, The Netherlands, 2011.

[11] Z. P. Bažant, "B. 10 - Analysis of pore pressure, thermal stress and fracture in rapidly heated concrete," in NIST special publication 919 - Proceedings International Workshop on Fire Perfromance of High-Strength Concrete, Gaithersburg, United States of America, 1997.

[12] K. van Breugel, C. R. Braam, C. van der Veen and J. C. Walraven, Betonconstructies onder temperatuur- en krimpvervormingen (BP2), Boxtel, The Netherlands: Aeneas, 1998.

[13] B. B. G. Lottman, Fire in bored tunnels - structural behaviour, during fire conditions, of bored tunnels made with a concrete segmental lining - MsC thesis TU Delft, Delft, The Netherlands, 2007.

[14] B. B. G. Lottman, E. A. B. Koenders and J. C. Walraven, "Towards a model for fire resistant design of concrete elements," in Proceedings of the 1st International Workshop on Concrete Spalling due to Fire Exposure, Leipzig, Germany, 2009.

[15] B. B. G. Lottman, E. A. B. Koenders and J. C. Walraven, "Macro-scale spalling model: a fracture mechanics versus pore pressure approach," in Proceedings of the 2nd International RILEM Workshop on Concrete Spalling due to Fire Exposure, Delft, The Netherlands, 2011.

[16] M. Hassanizadeh and W. G. Gray, "General conservation equations for multi-phase systems 1: averaging procedure," Advances in Water Resources, vol. 2, pp. 131-144, 1979.

[17] M. Hassanizadeh and W. G. Gray, "General conservation equations for multi-phase systems 2: mass, momenta, energy and entropy equations," Advances in Water Resources, vol. 2, pp. 191-203, 1979.

[18] J. M. Moran and H. N. Shapiro, Fundamentals of Engineering Thermodynamics - 5th Edition, Hoboken, United States of America: John Wiley \& Sons Inc., 2004.

[19] D. Gawin, F. Pesavento and B. A. Schrefler, "Modelling of hygro-thermal behaviour of concrete at high temperature with thermo-chemical and mechanical material degradation," Computer Methods in Applied Mechanics and Engineering, vol. 192, no. 13-14, pp. 1731-1771, 2003.

[20] C. T. Davie, C. J. Pearce and N. Bićanić, "Coupled heat and moisture transport in concrete at elevated temperatures - effects of capillary pressure and adsorbed water," Numerical Heat Transfer, Part A: Applications, vol. 49, no. 8, pp. 763-773, 2006.

[21] S. J. F. Erich, A. B. M. van Overbeek, G. H. A. van der Heijden, L. Pel, H. P. Huinink, W. H. A. Peelen and A. H. J. M. Vervuurt, "Validation of FEM models describing moisture transport in heated concrete by Magnetic Resonance Imaging," Heron, vol. 53, no. 4, pp. 225-246, 2008.

[22] J. van Kan, A. Segal and F. Vermolen, Numerical methods in scientific computing, Delft, The Netherlands: VSSD, 2008.

[23] E. Schlangen, Experimental and numerical analysis of fracture processes in concrete - $\mathrm{PhD}$ thesis TU Delft, Delft, The Netherlands, 1993.

[24] A. H. J. M. Vervuurt, Interface fracture in concrete - PhD thesis TU Delft, Delft, The Netherlands, 1997.

[25] G. N. Wells, Lecture notes course CT5123 - the finite element method: an introduction, Delft, The Netherlands: Faculty of Civil Engineering and Geosciences - Delft University of Technology, 2006. 


\section{MATEC Web of Conferences}

[26] D. L. Logan, A first course in the finite element method, Stamford, United States of America: Cengage Learning, 2012.

[27] N. Noda, R. B. Hetnarski and Y. Tanigawa, Thermal stresses, New York, United States of America: Taylor \& Francis, 2003.

[28] J. H. H. Fellinger, Shear and anchorage behaviour of fire exposed hollow core slabs - PhD thesis TU Delft, Delft, The Netherlands: Delft University Press, 2004.

[29] F. Hartmann and C. Katz, Structural analysis with finite elements, Berlin Heidelberg, Germany: Springer-Verlag, 2007.

[30] V. Yadama and K. England, Lecture Notes course CE 537: natural fiber thermoplastic composites - rule of mixtures, Pullman, United States of America: Washington State University - Departement of Civil \& Environmental Engineering, 2007. 